\title{
The Historian of Philosophy in Search of Sense
}

\author{
Anatoly Kolesnikov \\ Institute of Philosophy, Department of History of Philosophy \\ St. Petersburg State University \\ Saint-Petersburg, Russia \\ E-mail: kolesnikov1940@yandex.ru
}

\begin{abstract}
In the article, conditions of actualization interpretation and translation techniques of philosophical texts of non-Western philosophy are revealed. The author marks out features of hermeneutical procedures and their correlation with existentially rational approaches. The problem translatability of the texts and realization of possibility of the possibility of spiritual roll-call between the concepts of philosophers of the West and thinkers of the East is put.
\end{abstract}

Keywords-hermeneutical procedures; existentially-rational approach; translatability of texts; the autochthonic of Chinese philosophy; spiritual roll-call

\section{INTRODUCTION}

The contemporary world is still more and more often described as a co-existence of plurality of cultures and competing systems of their interpretation which has given birth to the discourse of multiculturalism. Some researches offer to characterize this status as the notion of "constructive pluralism". The discourse of interpretation found out the fact that not a single world picture explicating system of value and symbolistic forms of cultures and civilizations can rely on not-distorting world picture possession. It cannot offer universal regulations of existence to a human being. Such state actualizes the techniques of interpretation of mean's being of philosophical comparativistics and the meaningfulness of humanitarian techniques, providing the potential both of self-understanding of this or that culture and of understanding some otherness. On the other hand, problems of translating texts from one language into another one are also actualized, which is of utmost importance for the history of philosophy.

The history of philosophy comes across the experience of substantiation of the universals of West - European spiritual philosophy (starting from antiquity and up to modern times) and - on the other hand - comes across the conceptions of eastern philosophy taken broad mindedly and including the philosophies of Buddhism, Taoism, and Confucianism which produces the searches of methodologies of senses comprehension and distinctive bases of cultures and philosophies, for the purpose of realizing the possibility of mutual understanding.

\section{PRoblem of AdeQuAte TREATMENT OF EAST PHILOSOPHY}

The problem of adequate treatment of the broadmindedly understood Eastern philosophy and culture is recognized as one of the most dominating problems of hermeneutics and contemporary comparativistics. Halbfass W. in his monograph "India and Europe" (1981) [9[ noted, that in spite of advancement out the research in Eastern (Indian) philosophy, we are still far from its authentic understanding and reproduction. So, comparativistic philosophy undoubtedly is something more important than merely comparison - confrontation between philosophical systems; it is a "dialogic" way of comprehending the polyhedral nature of human beings and philosophical thought

When analyzing the cultures and texts of the countries in the East, Africa and Latin America for all the diversity of social existence, we come across the unpredictability of the results. Hence, humanitaristic of the West finds is difficult to give adequate answers.

It is incapable of outlining and disclosing the difficulties of the turn of the 20-21st centuries when weakness and insufficiency of conceptual apparatus and speculative models come to light. Universal conceptions competing with local contexts of native cultures lose them while explaining the present way and searching the new one. The term "archetype", introduced by K. G. Young for the purpose of fixation of cultural-psychological universals and appears to be helpful in some respect. Archetypes as prototype of cultures signify inseparability of the image and sense, of the symbols, and the essence of which is inexpressible by words. Yet, it recreates itself in real life quite energetically.

This structure of interaction does exist up to now. It is possible to realize their senses with the help of comparative methods and hermeneutical procedures of interpretation and understanding another culture along with other texts. The matter is not only in the rational foundation of real polyphony of philosophies but also in the exposure of some philosophical denominators, on the basis of which basic international macro projects in different spheres on the turn of the 21 st century (e.g. "worldwide ethnos", "global ethics" "worldwide philosophy of the future", "cross-cultural literature", "new research paradigm", etc.) had been worked out. 


\section{APPROACHES IN COMPARATIVE STUDIES}

Let's notice that the problem of translating texts and contexts of Eastern culture is constantly included into the sphere of comparatives works. The research proper begins with the creation of binary opposition: "Mine - Otherness", i.e. with dividing philosophy and culture into mine and some other ones. Traditionally, West-European and Eastern (African, Latin-American and so on) philosophical concepts appear as subject of comparison where they are examined as the greatest types of philosophy worldwide.

Philosophical comparative studies has at least logicalanalytic, rationalistic and hermeneutic, or existentialrationalistic approaches. The first approach - which is as a rule Eurocentric- is more anxious about the cognition of otherness, and the second one about its understanding. V.G. Lysenko disclosed the strategies of logical-analytical approaches. [4, P. 146-166]. She presented its realization at the place of well-known domestic easternists - Indologist V.K. Shokhin and sinologist J.A. Kobzev. Shokhin is founded on the fact that philosophy as some all-embracing standard essence is the bearer of steady patrimonial characteristics, independent neither of the epoch nor of the locus of forming. All that is not reduced to this ideal model can be explained by native peculiarities (which are not of interest). Meanwhile, the patrimonial notion of philosophy is established "a priori" is borrowed from European tradition or constructed on the basis of "categorical net" of WestEuropean philosophy. This is the way the methodology of Shokhin's strategy of comparison is logically developed: everything that is in accordance with the given model is accentuated (actualized) and is proclaimed valuable, i.e. as philosophy proper; everything that contradicts it is taken out of context. The empirical conclusions of Shokhin are the following: Indian philosophy is a certain invariant of worldwide philosophy, and that is why it is of great value because it "coincides" in many parameters with WestEuropean and above all with ancient Greek philosophy. [6, p. 102] But when reflecting upon the specificity of Chinese cultural tradition, Shokhin comes to the conclusion, that "philosophy" in ancient China remained on the level of "rudiments", i.e. was actually absent, so far as in the scheme of things it is not reduced to any ideal pattern. [8]

According to J.A. Kobzev, philosophical traditions of different cultures and civilizations are irrelevant to certain normative "pattern" but are the product of these cultures and civilizations. Thus, the concept "philosophy" is filled worth diverse senses and contents in different cultures. In a case like that Chinese philosophy can't, in point of fact coincide with European philosophy, any comparison is necessary for the historian of philosophy or for a researcher to be helped them designation "a certain sphere of intellectual universality in a language understandable by any European reader". [4, P. 157] In other words, West-European philosophy with its categorical general philosophical apparatus must be not a pattern, but an opposite background, on which non-European legacy heritage is seen quite clearly. [6, P. 105; 3, P. 17-55]

Kobzev's and Shokhin's strategies of comparison reflect old struggle between followings universalism and localism.
West-European intellectuals' utterances on Chinese philosophy almost always border on the denial of its importance. Hegel completes this tradition, and Herder consider it "purely local product". Academician V. M. Alekseev talks about absolute difference in ChineseConfucian culture with respect to West-European. As for Confucianism, the main field of European unreason ability is concentrated, as it is considered exotic, i.e. " an element of strange culture which is impossible to adopt". [1, P. 331] This exotic, as all Chinese culture is endured by Europeans keenly [2, P. 74], which means the impossibility for historians of philosophy to compare West-European and Chinese ideas.

As for Indian and West-European philosophies: they belong to single Indo-European cultural-genetic substratum when comparing not only their obvious distinctions but also their likeness are revealed rather easily and painlessly. In this sense, normative model withdrawn out of the context of West-European intellectual tradition is rightful from the point of view of logic-methodological and empirical analysis. It's not by chance that A.I. Kobzev supposes it possible to unite in future Indian and European traditions in order to emphasize still stronger the absolute autochthones and specificity of Chinese philosophy. Some researchers consider it possible to unite Latin-American and African philosophies together with European one, so far as in ancient times they didn't have philosophical thought, but the thought of contemporary times follows the European one.

\section{HERMENEUTICAL APPROACH}

Certainly, all these researches "try to explain their subject in the language of European studies, to create the system of parameters and ground control points which could help a well- educated reader to gain complicated exotic material, without denying its place in European culture". [4, P. 158] There and some other positions with respect to alien tradition. Hermeneutical, existentially-rational approach in philosophical comparative studies ascending to Dilthey and accentuating the possibility to understand "some another one" as it from within promotes it. Sinologists have it in the works by V.V. Maliavin, uploading the principal incompatibility of Chinese notional apparatus with the system of European logic. In other words, it is impossible to translate Chinese terms into European ones. That is why it is not worth comparing speculative notions about thinking and nature in the East and The West, but it is not worth "listening attentively to the soundless step ideas". [5, P. 23]

To counterbalance such negative strategy of comparison, E.A. Torchinov proposed positive existentially hermeneutical variant of comparison. Thus, in his collective work "Heidegger and Eastern philosophy", he proposes two approaches. One of them is direct addressing the biography and philosophical legacy of the German philosopher (the study of the degree of his acquaintance with Eastern philosophical systems and revealing of influence of Eastern thinking on his creative work. This approach is of interest but was not so fruitful for Torchinov. The second approach consist in searching some special spiritual roll-call between Heidegger's reflections and Eastern thinkers' intentions 
beyond the limits of the question: whether Heidegger himself was acquainted with these concepts. Such approach is of value because "it allows to examine both directions of thought in their openness and timeless ontological dialogic. When well applying such hermeneutical approach, the Eastern thought and Heidegger's texts become somehow mutual interpreting themselves and opening new horizons of metaphysical inquiring concerning the essence about the essential"'. [7, P. 191]

Let's designate another fact: the hermeneutical approach includes the component of rationalism peculiar to logicanalytical comparative studies. Mentioned Torchinov writes, that comparison of Heidegger's theories with Eastern ideas is not so much of interest, as the establishment of the level of effectiveness, and even as the universality of Heidegger's approach "and his acceptability for contemporary Eastern philosophy, aiming at gaining new horizons in the context of tasks and challenges of the 21 st century"/ [7, P. 163] In other words, the researcher is elucidating the perspectives for non-European traditions in the philosophy of Heidegger's approach. It is true that external reflection and subjective structure of attitudes while interpreting the text start contradicting interpreted broadmindedly Eastern thought. These settled recipes for searching the sense in the dialogues cultures all time put in the center of understanding the figure of mediator, i.e. of translator of philosophical texts, of its interpreter. As the connoisseur of several cultural traditions, the thinker promotes their interaction and their mutual influence. [10]

We know that musical notation appears in the role of a mediator art between the composer and performer like that the dialogue between various systems of ideas and traditional happens as a result of intellectually-volitional efforts of some peculiar personality of the translator and his philosophical culture. Only the historian of philosophy as a translator carries out interaction of heterogeneous philosophical cultures and exposes their senses common to all mankind. Thus, the interpretation of texts and their senses with certain purposes and putting placing the creator of new (conditionally adequate) intellectual construction is carried out. The sense of the arising construction assumes multiformal reflective connection between one culture and another filled with problems ontology. Synthesis of philosophical cultures takes place as the transformation of the translator's culture proper taking into account the experience of the culture of the given text, and that can be conceived as the spiritual form of intersubjective interaction. It is just here that the communication of primary matrix symbolic cultures takes place, and meta-thought of mankind availability are conceived in the being as such.

\section{STRATEGY OF FINDING-OUT OF INTERRELATIONS AND INTERFERENCES}

Parallels between society and culture - on the one hand and between knowledge and world outlook on the other hand come across in philosophy, which looks for connection between sociopolitical context and thought. E.G. Bourdieu and R. Collins introduce mediatory element between macrosociological variables such as social class and world outlook.
Bourdieu calls this element of intermediate group the field of philosophy. Collins calls it the space of attention. Theoretical purpose field and ecumenical metaphors should escape the situation where thought is the spontaneous expression of social and cultural being. The philosophical field and space of attention consist of Pleiades of actors have compelling points of view. They struggle more definitely for attention and gain an advantage for their own thought. Both Collins and Bourdieu consider philosophy as the effect of factors which are internal for philosophical field and space of attention. Besides, all external influences on these medium are refracted in the spheres of their own way of functioning; in other words, the thinker is under the external influence on his own logic of arguing. When we try to understand the thought of a philosopher we should first of all clear up the connection between these spheres. This methodological orientation comes to paying attention to local and concrete conditions, but not to socio-political macro-conditions. Moreover Bourdieu uses the nations nomos, illusion and doxa. They designate that it is worth differentiating its own object from other ones, taking part in the game, trusting its sense and remembering traditions. Hence, the choice of the philosophical point of view is determined by great number of reasons so far as philosophy doesn't possess absolute autonomy concerning other factors. This is a definite philosophical transdisciplinary gestalt, working "over" disciplinary divisions and using empirically actual basis and methodological reception in different traditions.

Revealing philosophical comparativistic intercommunications and mutual influences of East and European thought, just as like elucidating general by civilized tendencies in the development of philosophizing is more and more anxious about correctness of defining the notions West and East. However, the Near, Middle, Far East - these are different worlds: Judaic- Arabic- Muslim and Confucianism - Taoist - Buddhism - Hinduism - Shinto one. Doesn't the dialogue look like some game according to the rules of meta senses, world outlooks, cultural paradigms? The translator who is the same time the history of philosophy constantly fined himself on the boundaries of local cultures, when it is impossible to dissociate from them in order to give the sense of this or that term. On the other hand, as a representative of this or that philosophy, the translatorhistorian expresses "the spirit" of the people, nation, and epoch. But does he? Are philosophical Buddhism and practical Buddhism (having their own character in different countries and cultures), orthodox theology and everyday Christianity, Sufism enlightened and Sufism of dervishes? Are all they compatible? Where is the truth, or do we average out, schematize diverse forms of philosophical experience? Do we leave the stereotypes or pass on to the depths of linguistics?

\section{CONCLUSION}

If comparative investigation in the fields of culturology, philosophy and philology were oriented on searching the characteristics of similarities and distinction, then contemporary researches under the influence of postmodern are striving still more and more for absolutes of distinctions. 
They see only the different, another and often something else. This sharpens the attention to the problem of understanding and authenticity. Thus, hermeneutics becomes itself in the center of salving controversies. Although it is not worth absolutizing it within limits of hermeneutical idea, it should bring up the interpretational consciousness, it partially conduct contextualization, especially of one's own positions and prejudices. Apparently, it is worth examining hermeneutics as "fusion of horizons", "the process of interpretation" and "the art of understanding". The essential achievement of contemporary philosophical hermeneutics, which is of great importance for comparative studies of cultures of Russia, the West and the East is the problematization of the idea of depending the researcher on his own cultural values and standards. It originates from the hermeneutical facticity of Martin Heidegger, who, introducing the notion Dasein, proved that the structure of the primary understanding includes the impossibility for man to disengage himself from his own being. His being, his origin precedes him and determines him. Guided by this statement he fixed the historicity of the interpreter proper, who is always inserted in the context of tradition. The interpreter always comes to understanding the object, supported by his own experience, transferring the object to his own spiritual horizon. This process of understanding can only be tropological by its nature, as it involves something unknown into the presentation and makes it known to us with the help of figurative support. The thing is that lots supper from untranslatability and that means the interpretation is not always complete, but approximate. Just like that there remains in the translation a certain habitus the residue of subjectivity from cross-cultural intercourse with the text.

In the end, we should determine concerning the methodology of comparative studies and philosophical translations. We should pay attention to traditional ways method of research which have always been anxious concerning objectivity, historic-objectiveness - genetic validity, unify and diversity of the forms of the world exploration and the forms of philosophizing in the limits of different socio-cultural spaces and in the mechanisms of collective memory.

\section{REFERENCES}

[1] V.M. Alekseev. Science about the East. Articles and documents. - M.: Science, 1982.

[2] M. Bankovskay. I am a worker-enthusiast // Traditional culture of China. M: Science, 1983.

[3] A.I. Kobzev. Specifics of philosophical and scientific methodology in traditional China // Ethics and ritual in traditional China. The collection of articles. - M.: Science, 1988. - P. 17-55.

[4] V.G. Lysenko. Comparative philosophy in Russia // Comparative philosophy. - M,: Oriental literature. 2000. - P. 146-166.

[5] V.V. Maliavin. Chzhuan-tszy. - M.: Science, 1985.

[6] A problem the East-West in the history of philosophy and unity of world historic-philosophical process // Philosophical sciences. - 1988. № 7.

[7] Heidegger and East philosophy: searches complementarity cultures. SPb.,SPBGU, 2001
[8] V. K. Shokhin. Brahmanical philosophy. - M.: Science, 1994.

[9] W. Halbfass. Indien und Europa. Perspectiven ihrer geistigen Begegnung. Basel Stuttgart. 1981.

[10] J.A. Taber. Trasformative Philosophy. A study of Sankara, Fichte and Heidegger. University of Hawaii Press. Honolulu, 1983. 